\title{
Online to offline teaching model in optics education: resource sharing course and flipped class
}

Xiaotong Li, Zhaofeng Cen, Xiangdong Liu, Zhenrong Zheng

Xiaotong Li, Zhaofeng Cen, Xiangdong Liu, Zhenrong Zheng, "Online to offline teaching model in optics education: resource sharing course and flipped class," Proc. SPIE 9946, Optics Education and Outreach IV, 99460R (27 September 2016); doi: 10.1117/12.2237823

SPIE Event: SPIE Optical Engineering + Applications, 2016, San Diego, California, United States 


\title{
Online to offline teaching model in optics education: resource sharing course and flipped class
}

\author{
Xiaotong Li, Zhaofeng Cen", Xiangdong Liu, Zhenrong Zheng \\ State key laboratory of modern optical instrumentation, College of optical science and engineering, \\ Zhejiang University, Hangzhou 310027, P. R. China
}

\begin{abstract}
Since the platform "Coursera" is created by the professors of Stanford University Andrew Ng and Daphne Koller, more and more universities have joined in it. From the very beginning, online education is not only about education itself, but also connected with social equality. This is especially significant for the economic transformation in China. In this paper the research and practice on informatization of optical education are described. Online to offline $(\mathrm{O} 2 \mathrm{O})$ education activities, such as online learning and offline meeting, online homework and online to offline discussion, online tests and online to offline evaluation, are combined into our teaching model in the course of Applied Optics. These various $\mathrm{O} 2 \mathrm{O}$ strategies were implemented respectively in the autumn-winter small class and the spring-summer middle class according to the constructivism and the idea of open education. We have developed optical education resources such as videos of lectures, light transmission or ray trace animations, online tests, etc. We also divide the learning procedure into 4 steps: First, instead of being given a course offline, students will learn the course online; Second, once a week or two weeks, students will have a discussion in their study groups; Third, students will submit their homework and study reports; Fourth, they will do online and offline tests. The online optical education resources have been shared in some universities in China, together with new challenges to teachers and students when facing the revolution in the e-learning future.
\end{abstract}

Keywords: Applied optics, optical education, resource sharing course, online to offline, online education, flipped class

\section{INTRODUCTION}

In 2011 the platform "Coursera" was created by Prof. Andrew Ng and Prof. Daphne Koller. In less than two years the fever of Massive Open Online Courses (MOOCs) spread all over the world. Millions of people were attracted by online courses. This opens the door for equalizing the education rights between the people who come from different degrees, different countries and areas. China is still a developing country, although we have made great progress in university education. Now we also face the problem of social equality including education owing to the unbalance in university education resources. In the period of the National Twelfth Five-Year Plan, the Education Ministry of China developed a platform named "Icourses" for pushing the procedure of opening and sharing courses forward. The undergraduate course Applied Optics in Zhejiang University is a National Excellent Resource Sharing Course. The videos, PowerPoint files and other resources of the course were uploaded to the website www.icourses.edu.cn in 2013.

In this case new problems appear: What do MOOCs mean to higher education ${ }^{1}$ ? Is the online resource equal to online education? What does the online education bring to us? How can our education idea and teaching procedures keep up with the e-learning time? Novel techniques give us tools, and in reality we have found that teachers take more care of how to use the techniques for teaching, in many cases this is only about to let the students in distance hearing, watching high level course videos and experiments. However, the revolutionary meaning of online education is not comprehended in deep. So it is difficult to avoid the situation of "old wine in new bottles".

In the same period the high dropout rate of MOOCs is noticed. In 2013, it was reported by BBC that Harvard planned to boldly go with Small Private Online Courses (SPOCs) ${ }^{2}$, and we were already "post-MOOC" ${ }^{3}$. In 2014, we started the project of optical education reform named "Sharing courses for the discipline of optical engineering in China", this is supported by the Sub-division of Teaching Guidance Committee of Education Ministry of China for the Engineering of Optics and Photonics, and is to implement as SPOCs. Now let us remember the constructivism learning theory. This was

*cenzf@zju.edu.cn; phone (86)571-87952302; fax (86)571-87952302; opt.zju.edu.cn 
put forward by Dr. Jean Piaget. He emphasized the activity of learners. Learning is a constructive procedure based on the learners' original knowledge and experiences, and is completed in social culture interaction. Constructivism based learning or learner-centered learning was researched and applied in many courses ${ }^{4}$. If a student learns a course only by watching online video, or adding some more online studying activities, he or she will have less chance to make the personality progress, such as critical, cooperative and sharing spirits, communication and expression capabilities in multi-cultural circumstance. In universities, the conversation between teachers and students is an important aspect in one's career, and has much more significant meaning than learning a course. This is why we prefer SPOC.

Furthermore, Applied Optics is the first fundamental optical course in the department of optical engineering. At the beginning the students learn it highly motivated, but as the class goes on, especially when the stops in optical system comes into their mind, these new concepts, principles, and relationships in drawing and calculation make them feel confused. Conversation and interaction are also help the students solve these problems by different methods.

We have implemented the discussion in study group and flipped class from 2011. This made our course be welcome by the students ${ }^{5}$. From the autumn-winter semester of academic year of 2014-2015, we offered our first online class. To meet the change of this period, we introduced the $\mathrm{O} 2 \mathrm{O}$ teaching design into the class from then on, including online and offline teaching procedures and pluralistic evaluation system, according to the opening idea of education and the constructivism educational theory. Independent learning and pluralistic evaluation have been applied in these years backing our network platform. This is quite different from conventional education reform. We have implemented this teaching strategy for several semesters and have shared it in some universities in China as a teacher training course of our specialty.

From the standpoint of students, the learning procedure includes online study, online and offline discussion, study reports presentation, online and offline tests or examination.

\section{O2O TEACHING DESIGN}

\subsection{Online learning and offline meeting}

In autumn-winter semester of the academic year of 2014-2015, we offered the first online class in which 17 students come from 3 grades. Because of the different schedule of different grade, we had no fixed class time for giving them lecture. Instead of conventional lessons in classroom, we helped the students to make an online learning plan. We asked them to watch the videos weekly, and every two weeks we had an offline meeting to sum up what they learned, and to instruct how to learn the next item, what problems they would face, and what relationships or optical drawings they should understand. For example, the coordinate transfer regulation, the physical meaning of Lagrange-Helmholtz invariable, the Gaussian formula and Newton formula and imaging relationships in lens systems, the beam limit and diaphragm, how to arrange the optical stops so as to match each other in classical optical systems, such as microscope and its illuminator, Kepler telescope and its image inverter, etc.

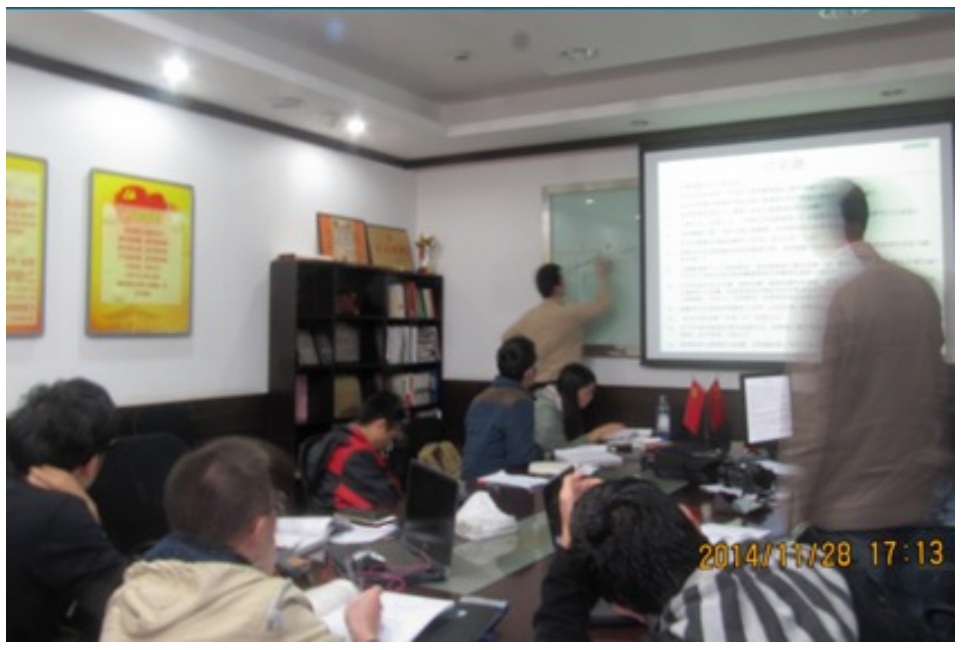

Figure 1. A student was expressing his opinion at the small class meeting 
As Prof. Koller said in her speech, if she asks in class a question, $80 \%$ of the students are still scribbling the last thing she said, 15\% are zoned out on Facebook (in China it is Wechat or QQ), and then there is a smart one in the front row who blurts out the answer before anyone else has had a chance to think about it. How to give everyone the chance to express oneself? This is not a difficult problem in a small class of 17 students. At the regular meeting, we got out typical questions and inspire the students to answer and give their explanation. For some of the questions they had different answer, we appreciate the discussion chances from different thinking. Figure 1 is a photo in which a student was presenting his opinion. Once, we noticed a student had a glimpse in his eyes with slow move of his mouth. Under the encouragement of us, he proposed his point of view and induced a discussion about it. Although the analysis and derivation denied his opinion, his learning status greatly changed. Then he became an active sunny boy and now is helpful for others.

\subsection{Online homework and cross-revise}

From the spring-summer semester of academic year of 2014-2015, we have brought some online self-study parts of the course into middle classes. Here middle class means there are dozens of students. The following strategies are implemented in small and middle classes.

In Applied Optics there are much formulas and drawings and exercises. The students need to do their homework weekly. In the conventional class they hand in the homework exercise books. In $\mathrm{O} 2 \mathrm{O}$ classes the students are required writing the homework on exercise books and taking photos, then submitting their homework as .doc files with the photos pasted in through the course website before deadline. Then we make a cross-revise relationship table for them. According to the table, everyone's homework has the chance to be graded by different classmates throughout the semester.

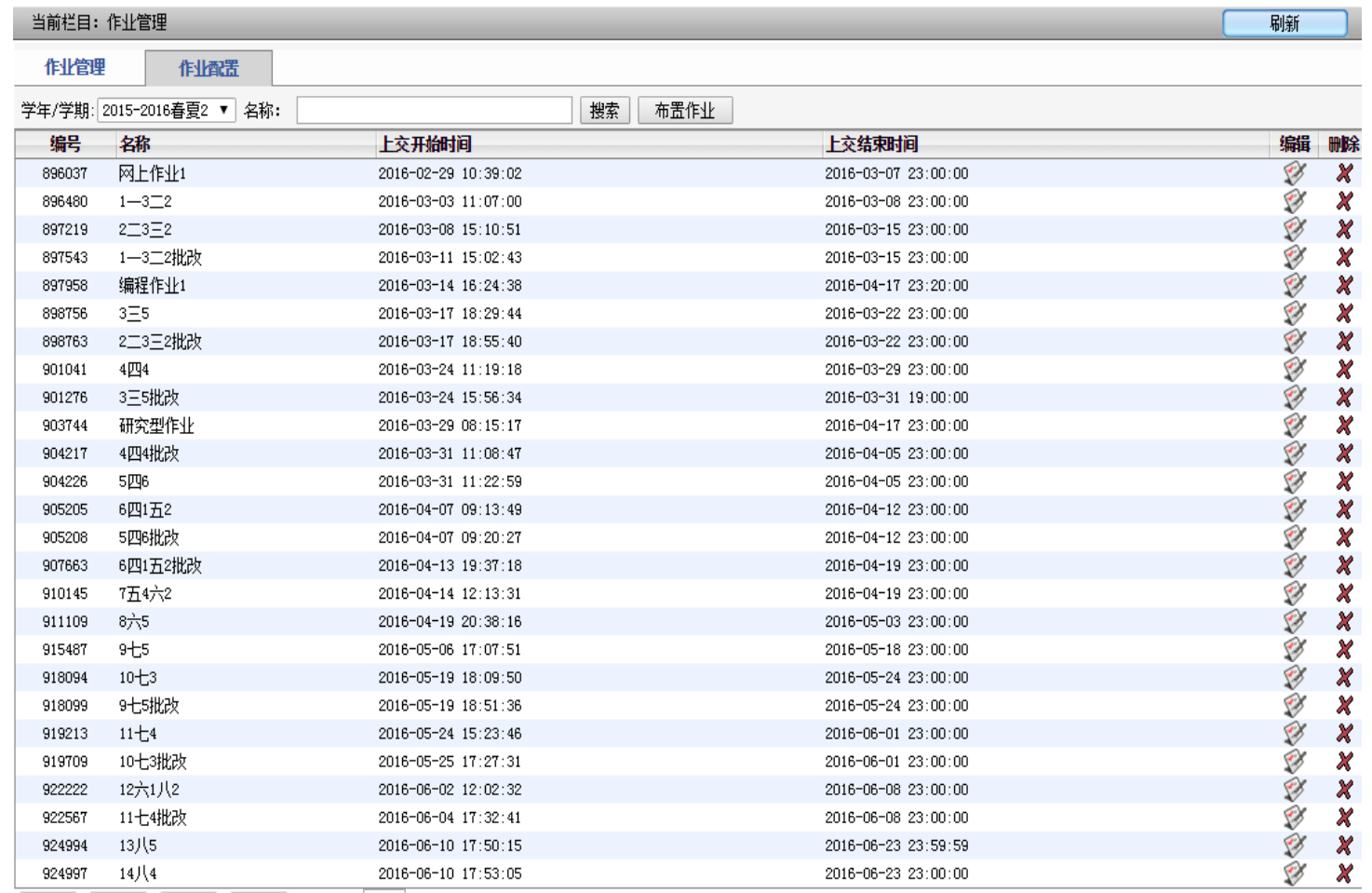

Figure 2. Homework assigned in spring-summer semester 2015-2016

From figure 2 we can see the homework we assigned in the spring-summer semester of the academic year of 2015-2016. Figure 3 shows the submitted homework. The deadline is usually set at 23 o'clock. Cross-revise makes the students think about other's solving methods and is helpful for them to broaden their view and promote critical thinking. Otherwise, if the homework is graded by the instructor or assistant, the students often have the psychological dependence, and focus on what is correct or not, but some of them rarely concern why. Now the cross-revise strategy goes over much better. In a sense, grading homework provides a different viewpoint of self-review or self-observation. 


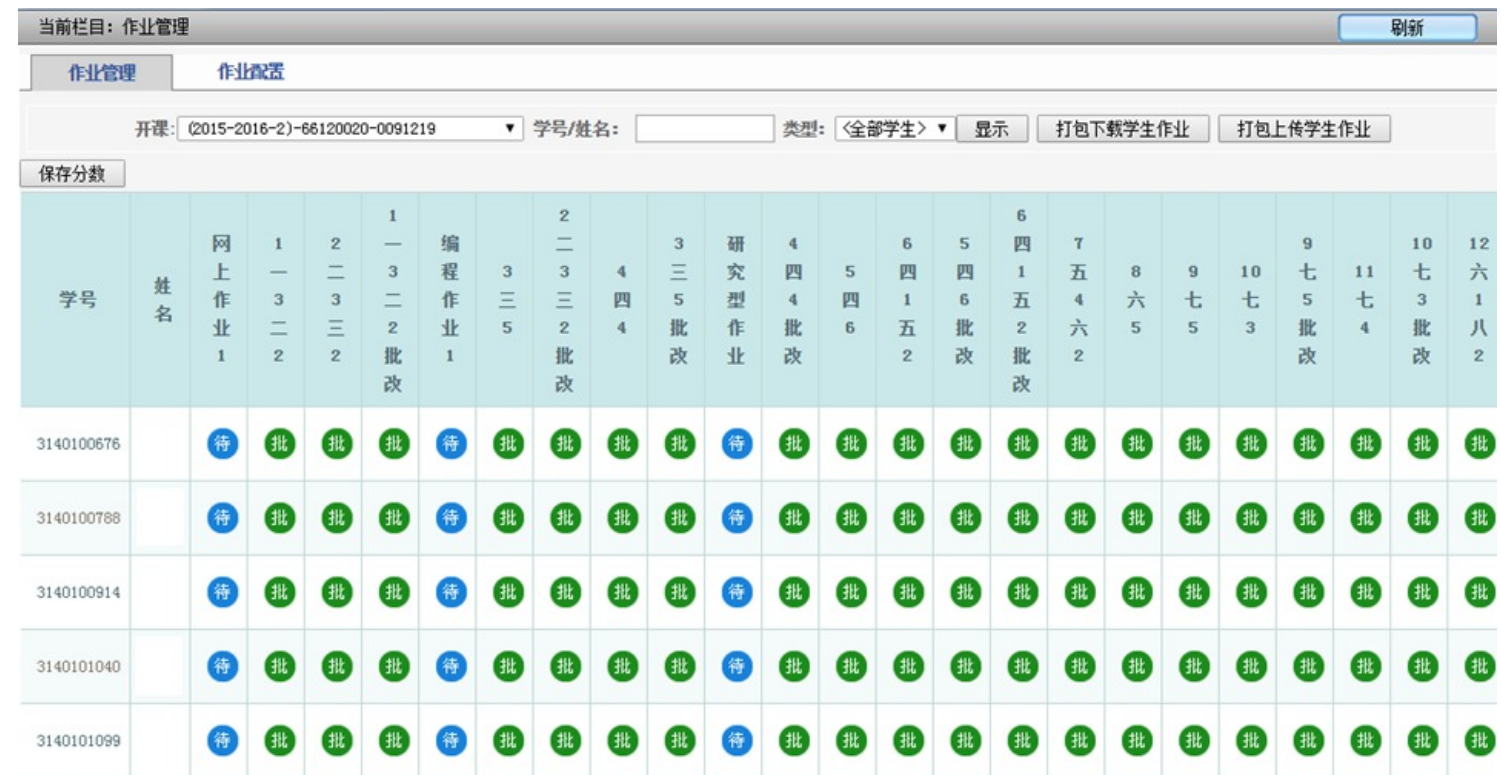

Figure 3. Homework submitted by the students in last spring-summer semester

\subsection{Online to offline discussion and group work}

In our teaching, discussion is a very important process. At the website we have a forum for discussion, but it is difficult to keep real-time response. In addition, for each teaching class we create a QQ group for online discussion. In any time if any student has question, he or she could put it in QQ group and any other people includes instructor, assistants and students could answer it. Online discussion expands the learning space from conventional classroom to anytime and anywhere. We often take part in the discussion, or observe probable arguments wherever we are, the only condition is we can online.

In MOOC, students often learn in a group in which the people come from the same country or time area or speak the same language. In our SPOC classes, the students are also divided into several study groups. One group consists of about 10 people. Now we have developed following three kinds of activities in study groups:

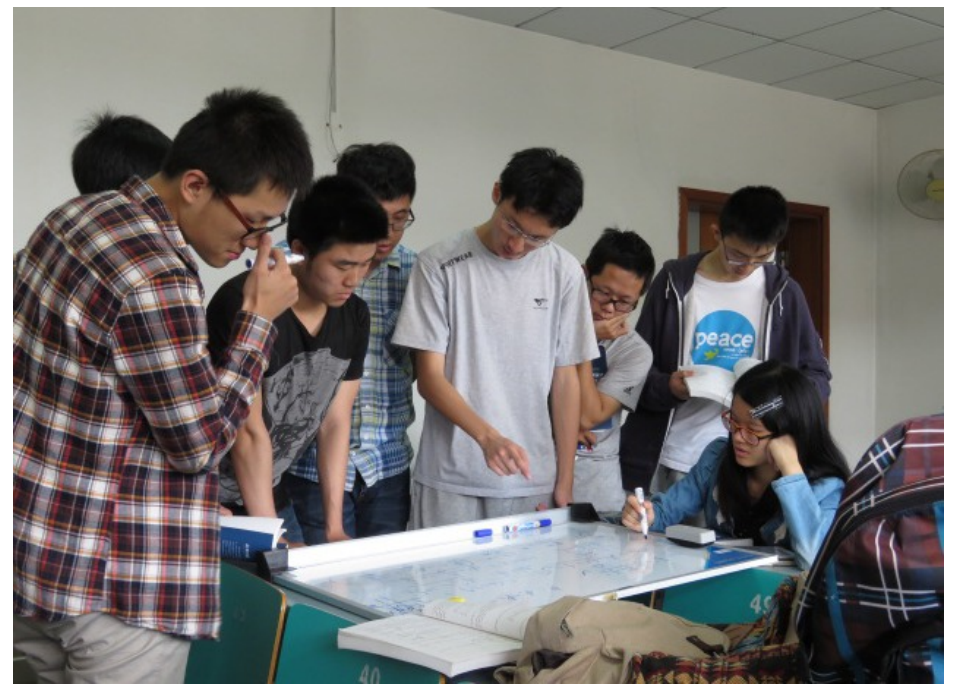

Figure 4. Flipped class: a study group is in discussion 


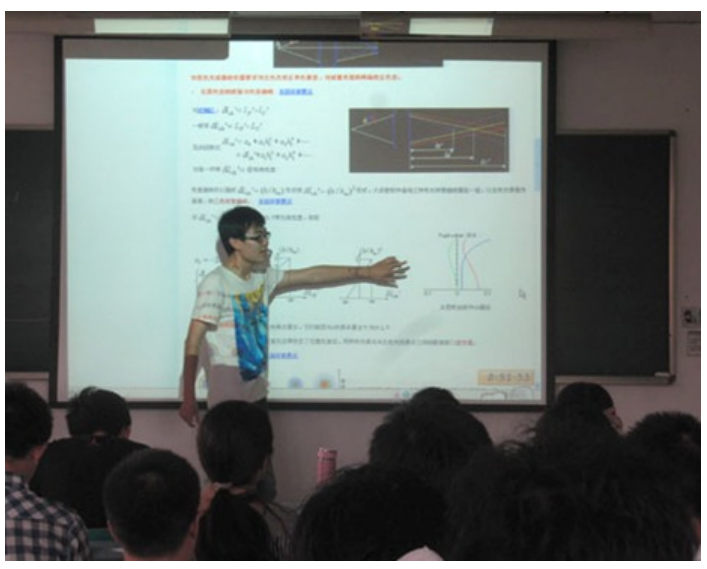

Figure 5. Flipped class: a group representative is giving a report

(1) Flipped class ${ }^{5}$. The students have watched the online videos we assigned then come to the class for discussion. They present their questions in self-learning, exchange their comprehension, review the important contents and drawings, complete the group discussion reports and give presentation as shown in figure 4 and figure 5. Mid-term examination is also a good chance for testing their study results. We usually arrange a discussion after it. The student in figure 6 was explaining his answer.

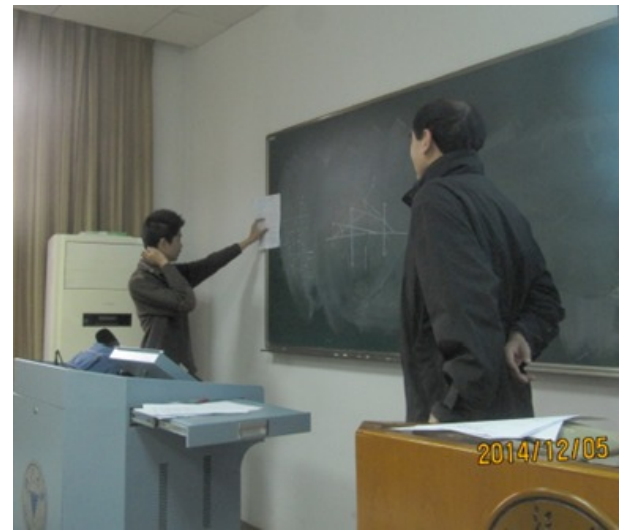

Figure 6. A student was explaining his answer at the meeting after mid-term examination

(2) Develop simple program. In this activity a study group consists of about 10 people is divided into 3 or 4 small groups. A simple program such as paraxial ray tracing, finding focal length or calculating cardinal point positions is developed by cooperation in each small group. The group head will work as a project leader to organize the process and merit every member according to one's contribution. At the same time the member will not only take care of his own work, but also consider about how to fit others requires as a programmer, for example, the input and output of the subroutine. These promote successively the team spirit of our students. By the way, we have another short term of two weeks in summer to practice optical system design and ray tracing programming.

(3) Produce micro videos. Optical drawing and principle derivation is basic skills for optical learner. In Applied Optics course some typical drawing skills are showed by online micro videos. Based on the situation that every student has own mobile phone to take photos or videos, we set the group homework of micro video production. The students are very interested in the task, as this mean they will contribute their work in sharing learning resource. When we set a task of micro video production about Cartesian coordinate solve when light transmits through a prism or prism system, the students made very good works but the "micro" videos were too long. We had to limit the video length 
of 3 minutes. Some of the micro videos made by the students with the explaining of young people have been uploaded to the course website and can be watched all over the world.

\subsection{Online tests}

We have developed a large number of online test questions. For every chapter or subject we give an online test. This is effective for improving the learning status. For a long semester the students complete 10 times of online tests. All of them agree that they find their disadvantages by the tests. In figure 7 a test is ongoing. From this figure we can see that the questions are not very complicated, but the wrong answers are well designed for showing typical mistakes. We give the students 3 chances to finish the test, and each chance is 5 minutes long. So when one makes a mistake, he or she can review the relative knowledge and then take the next chance.

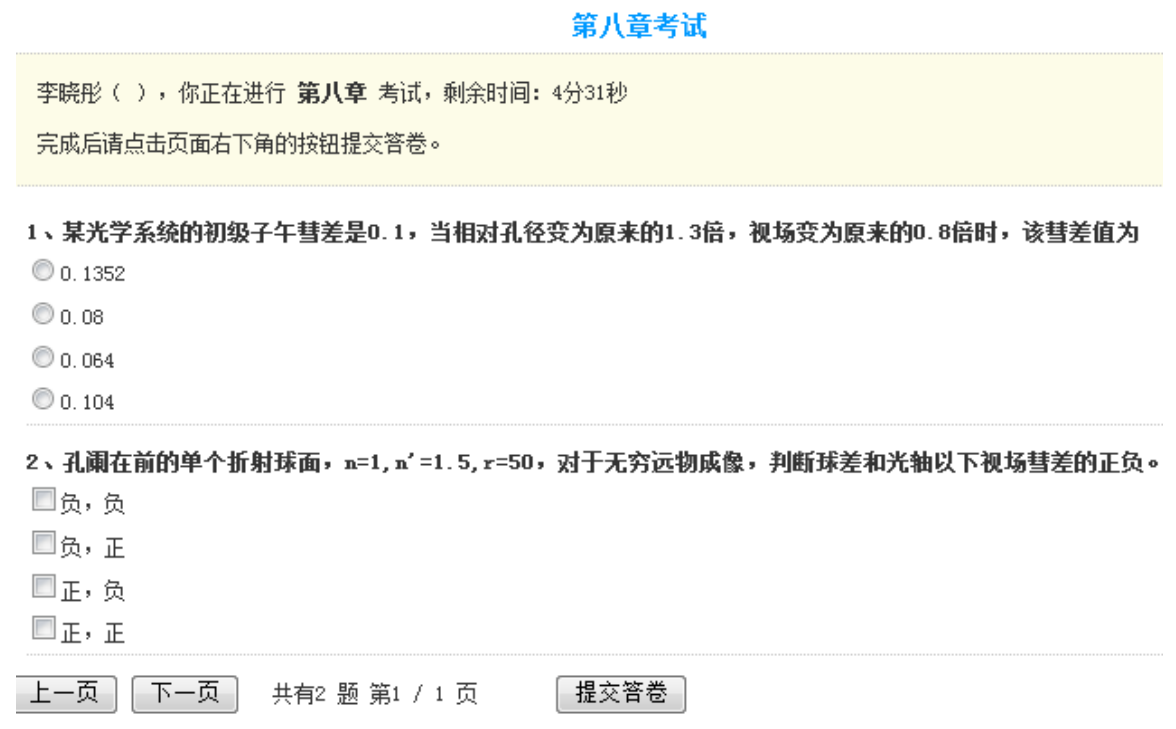

Figure 7. An online test is on going

\section{PLURALISTIC EVALUATION SYSTEM}

Our $\mathrm{O} 2 \mathrm{O}$ teaching strategy consists of a variety of teaching methods. This naturally causes the pluralistic evaluation system. In this system classical examination, homework and cross-revise, online test, and flipped class all be considered.

Need to be pointed out is that in table 1 the score of experimentation is graded by the experiment instructors and the score of discussion and flipped class is graded by the group leader according to the distribution of every member. In the final examination we give the students a whole evaluation on choice questions, optical drawing, paraxial imaging and layout calculation of optical systems such as telescope, microscope, photographic system or projection system. Aberration theory is also an important part. Mid-term examination is focused on the part of geometrical optics including the paraxial theory of spherical, plane systems and perfect systems.

Table 1. Pluralistic evaluation system

\begin{tabular}{|ll|}
\hline \multicolumn{2}{|c|}{ PLURALISTIC EVALUATION SYSTEM } \\
\cline { 1 - 1 } Item & Score ratio \\
\hline Final examination & $45 \%$ \\
Mid-term examination & $10 \%$ \\
Homework and cross-revise & $12.5 \%$ \\
Experimentation & $12.5 \%$ \\
Discussion and flipped classroom & $15 \%$ \\
Online test & $5 \%$ \\
& \\
\hline
\end{tabular}


The proportion of each part is shown in table 1. Undoubtedly the final examination has the largest proportion in the system. However, most of the students got their scores in final examination matched with their usual performance.

\section{SHARING TEACHING RESOURCES AND STRATEGIES}

Now more than 220 universities and colleges have disciplines in the field of optics and photonics in China. The teaching conditions and the students' qualities are very different. In the project of "Sharing courses for the discipline of Optical engineering in China", we play the role of researcher and developer. As a teaching resource provider, we hope that we can profit our resources to the general student all over China, and help them to study better.

From autumn 2014, we have updated a quantity of teaching resources and provided Applied Optics course at 3 websites with different organization formats. Till now there are 7 universities play the rolls as teaching resource provider, and 15 universities use these resources. Many teachers of these universities and colleges are interested in the $\mathrm{O} 2 \mathrm{O}$ teaching. We have communicated the idea and optics education reform efforts with them. As shown in figure 8, we went to Qingdao last year to introduce our work in Ocean University of China.

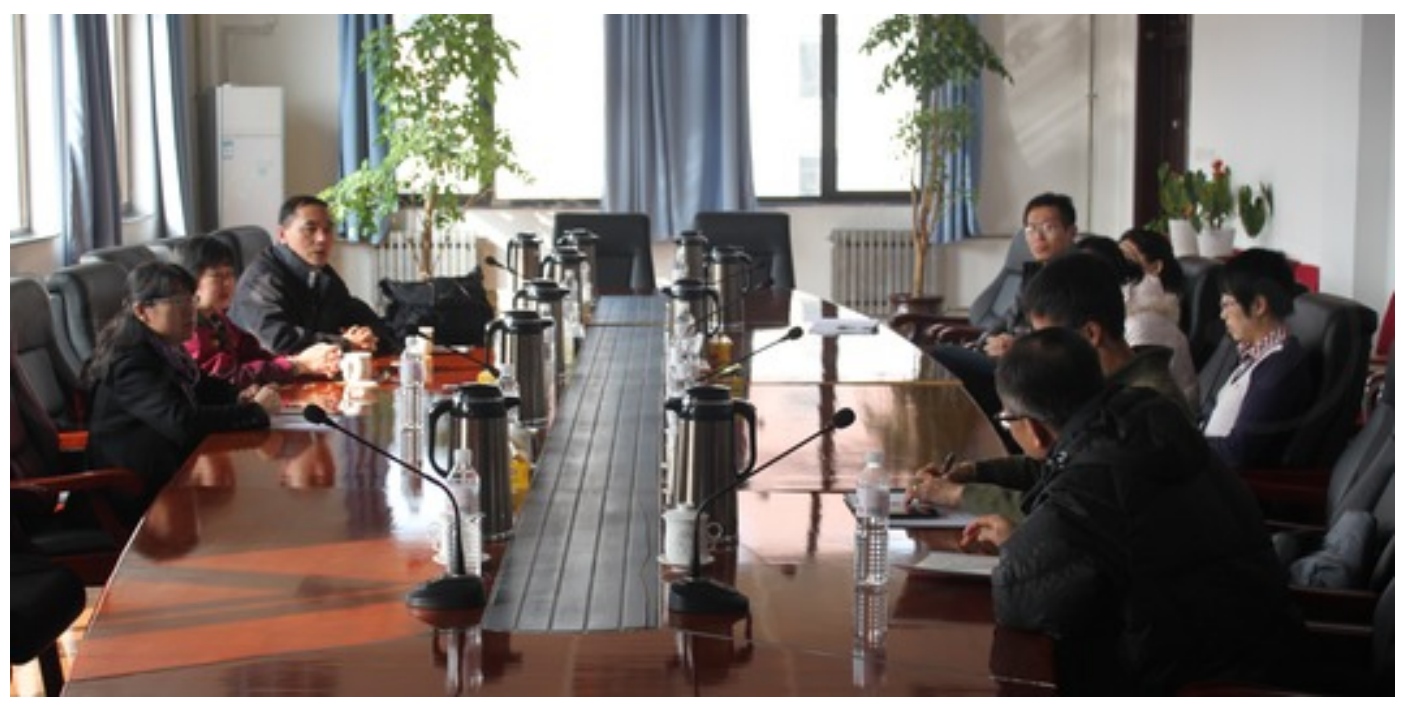

Figure 8. Introduce our teaching reform in Ocean University of China

\section{CONCLUSION}

We will have an e-learning future, a lifelong education era. The idea of teachers and students is changing. Computer, internet and mobile phone are always with us, and young students are interested in getting information from network by nature. Sharing education resource and $\mathrm{O} 2 \mathrm{O}$ teaching are not only a reform in optical education, but also meaningful in today's education reform. From the above there are some challenges to teachers and students:

(1) The students should be more activity, have the ability to manage one's time, be willing to communicate and cooperate with others. Whenever having questions, one is like to find information online, discuss it and share idea.

(2) Comparing with the lessons in conventional class, teachers should take more care of general teaching design and communicate with the students directly. We should focus on knowledge construction and ability development at the e-learning circumstance.

(3) Teachers should open their mind, and have the democratic style when interchanging with the students, and can manage the important and difficult points, and make these key points become comprehensive knowledge.

(4) Teachers should be senior netizens who can instant messaging with students, with good vocational spirit and the philosophy of opening, communication, cooperation and sharing. 
At the end of last semester, we made a poll in the students. The poll showed: $97 \%$ of the students satisfied the group leader's work and the group activities; $100 \%$ can think about other's opinions, and try to solve problems and get balance between different ideas through negotiation; 97\% think that they will be harmonic with the people who have different cultural backgrounds; $83 \%$ have self-confidence about their oral, writing and other communication skills; all students are willing to undertake their work in study group; all the students think that our online resource is helpful for their learning.

\section{ACKNOWLEDGEMENT}

All the work in this paper is supported by the Sub-division of Teaching Guidance Committee of Education Ministry of China for the Engineering of Optics and Photonics (Sharing courses for the discipline of Optical engineering in China) and the project of Education Ministry of China (National Excellent Resource Sharing Course).

\section{REFERENCES}

[1] Tu, C. H., McIsaac, M., Doyle, R., Aydin, H. and Ozkul, A. E., "A cycle of online education ecstasy/agony: To MOOC or not to MOOC," Proc. IEEE Annu. Conf. Int. Counc. Educ. Media, 2013, 6820221, (2013)

[2] Sean, C., "Harvard plans to boldly go with Spocs, " BBC, 24 Sept.2013, <http://www.bbc.co.uk/news/business$24166247>$

[3] Kang, Y. Q., "An analysis on SPOC: Post-MOOC era of online education," Tsinghua Journal of Education, 35(1), 85-93 (2014).

[4] Jeanne, S. and Ahmad, A. H., "Design of learner-centered constructivism based learning process," Proc. of the Federated Conference on Computer Science and Information Systems, 2012, 1159-1164 (2012)

[5] Li, X. T., Cen, Z. F., Liu, X. D. and Zheng, Z. R., "The resource sharing course applied optics: flipped class model and MOOC-like construction," Proc. of the Third Teaching Symposium of the Discipline of Optical Engineering in China, 2014, (2014) 